\title{
La variabilidad del precio en el contrato de construcción
}

\author{
María Sara Rodríguez Pinto*
}

\begin{abstract}
RESUMEN
¿Cómo se explica el fenómeno de que muchas obras empiecen con un precio y terminen con otro? ¿Puede ser definitivamente fijo e invariable el precio inicial de un contrato de construcción? El objetivo de este artículo es explicar la variabilidad a partir de los usos de la industria y de los efectos que producen los diversos pactos en el precio. La metodología es cualitativa a partir de un enfoque hermenéutico de fuentes normativas y jurisprudenciales, así como la revisión de referencias bibliográficas del ámbito jurídico y de ingeniería de la construcción. La bipótesis que se defiende es que el precio inicial del contrato es una estimación del precio final, único, fijo e invariable del contrato. El precio es el precio final. Esto se demuestra con la interpretación del contrato, labor que corresponde realizar al juzgador en materia de litigios relativos a diferencias entre el precio inicial y el precio final.
\end{abstract}

Chile - derecho de los contratos - precio - ingeniería de la construcción

\section{The construction contract price variability}

\begin{abstract}
How the phenomenon is explained that many works start with one price and end with another? Can the initial price of a construction contract definitely be fixed and unchanged? The objective of this article is to explain the variability from the uses of the industry and the effects produced by the various possible pricing clauses. The methodology is qualitative based on a bermeneutic approach of normative sources and cases, as well as the revision of bibliographic references in the legal field and construction engineering. The hypothesis is that the initial price of the contract is an estimate of the final price, unique, fixed and invariable of the contract. The price is the final price. This is demonstrated by the interpretation of the contract, an effort that belongs to the judge in litigation about differences between the initial price and the final one.
\end{abstract}

Chile - contract law - pricing - construction engineering

* Licenciada en Derecho, Pontificia Universidad Católica de Chile. Doctora en Derecho, Universidad Autónoma de Madrid, España. Profesora de Derecho Civil, Universidad de los Andes, Chile. Correo electrónico: msrodriguez@uandes.cl.

Este artículo es producto del proyecto Fondecyt Regular (2015) № 1150634.

Artículo recibido el 25.4.2019 y aceptado para su publicación el 19.8.2019. 


\section{INTRODUCCIÓN}

$\mathrm{E}$ n el contexto chileno hay literatura que se manifiesta escéptica respecto de la eficacia de los pactos de invariabilidad en los contratos de construcción ${ }^{1}$. Recientes sentencias de la Corte Suprema de Chile aceptan modificaciones al precio, aunque se trate de obras públicas y el precio se haya pactado por suma alzada ${ }^{2}$. La ingeniería se esfuerza por encontrar técnicas para el manejo de riesgos ${ }^{3}$. La pregunta es por qué se produce el fenómeno de la variabilidad y qué valor tienen los pactos en el precio, especialmente el pacto de suma alzada.

Nuestra hipótesis es que el precio del contrato es una estimación del precio final o definitivo. Este valor inicial sirve para fijar la cuantía del contrato, las garantías o las pólizas de seguro que debe tomar el contratista a favor del mandante, la cuantía del anticipo del mandante (cuando lo exija el contrato), y las devoluciones y retenciones de los estados de pago. Puede servir para determinar anticipadamente la utilidad del contratista. El precio inicial puede pactarse como precio único o suma alzada por la ejecución de toda la obra. Sin embargo, los efectos de este pacto dependen del desarrollo del proyecto y de la previsibilidad de contingencias durante la ejecución. La invariabilidad del precio inicial solo es posible en ciertas obras; y la variabilidad por causas ajenas al desempeño del contratista forma parte del contrato.

Para resolver litigios de variaciones en el precio, el juez debe interpretar el contrato tomando en cuenta la intención de los contratantes más que "lo literal de las palabras"4. En este tipo de contratos, especialmente organizado por el oficio de los que mandan y ejecutan obras de construcción, el juez debería considerar que "las cláusulas de uso común [que] se presumen, aunque no se expresen" práctica que hayan hecho [del contrato] ambas partes, o una de las partes con aprobación de la otra"6. Mandantes y contratistas procuran anticiparse y prever las variaciones; que, de suyo, parecen imposibles de incorporarse todas en la previsibilidad del contrato. La variabilidad del precio forma parte del contrato y es un factor conocido por los que operan en la industria.

${ }^{1}$ Albornoz, 2011, pp. 397-415; Southerland, 2014, pp. 161-195. Este trabajo examina el contrato que tiene por objeto único la ejecución de una obra, con planos y especificaciones (arquitectura, diseño e ingeniería) proporcionados por el mandante. Los contratos cuyo objeto es más amplio, por ejemplo, contratos EPC (Engineering, Procurement \& Construction) o contratos BOOT (Build, Own, Operate \& Transfer) pueden modificar algunas de las conclusiones de este trabajo. Acerca de estas diferencias, véase Prado (2014), pp. 765-783. Los contratos BOOT se regulan en Chile por la ley de concesiones de obras públicas (texto refundido, coordinado y sistematizado: D.S. N ${ }^{\circ}$ 900, de 2017).

${ }^{2}$ Corte Suprema de Chile, 30.8.2016, rol 33634-2015 (OHL con Fisco, 2016); Corte Suprema de Chile, 7.7.2017, rol 52960-2016 (Obras Especiales con Serviu del Bio-Bí, 2017).

${ }^{3}$ Huidobro, 2004, pp. 397-415. Ver también, Bunni,2003, passim.

${ }^{4}$ Artículo 1560 CCch. Respecto de formación del contrato, Wagemann y Mereminskaya, 2017, pp. 7-24; de la integración del programa de trabajo en el contrato, FLEISCHMANN y LEón, 2017, pp. 93-115.

5 Artículo 1563 CCch.

${ }^{6}$ Artículo 1564 CCch. 


\section{Metodología y MATERIALES}

El artículo se apoya en el estudio analítico de fuentes normativas y jurisprudenciales. Se atribuye valor a referencias bibliográficas de la ingeniería de la construcción que demuestran que es enseñanza pacífica en la industria la estimación de precios en las propuestas, los anticipos del mandante, las garantías del contratista y los pagos provisorios mediante estados de pago según el avance físico o el porcentaje de ejecución del proyecto, hasta la liquidación final del contrato, hecho que ocurre solo después de la recepción definitiva de la obra por la autoridad urbanística competente. El uso de la industria se compara con las convenciones y normativa por las que mandante y contratista determinan jurídicamente el precio del contrato.

Lo expuesto se desarrolla de la siguiente manera. En un primer epígrafe (§ I.) se examinan los factores técnicos y económicos que se consideran en la industria para establecer el precio de las obras de construcción. En el segundo (§ II.) nos referimos a la operación jurídica que consiste en la determinación del precio. El tercer epígrafe de este artículo es un análisis del pacto de invariabilidad y sus efectos (§ III.). El último (§ IV.) se refiere a las consecuencias de distintos eventos en el precio del contrato, según cual sea la convención de las partes. Los factores técnicos y económicos, traducidos en diversos pactos del precio, demuestran que la variabilidad forma parte del contrato; y que solo es posible conocer el precio definitivo al final del contrato, recibida definitivamente la obra por la autoridad competente.

\section{FACTORES TÉCNICOS Y ECONÓMICOS DEL PRECIO}

El precio del contrato es un todo que incluye costos directos e indirectos, gastos generales del contratista, eventuales provisiones por contingencias y la utilidad del proponente ${ }^{7}$. Ofrecemos a continuación una síntesis de estos conceptos por su interés con la operación jurídica de determinación del precio y en las consecuencias en la estabilidad de este.

\section{Los costos directos}

Para la ingeniería, costos directos de ejecución son "todos los que están asociados directamente con la obra", como "mano de obra, materiales y equipo directamente comprometidos en su ejecución" 8 . Toda la organización del contratista, directamente empleada en la ejecución de la obra, desde capataz a jornalero, e incluso supervisores, es

${ }^{7}$ Arriagada, 1988, p. 453; De Solminihac y Thenoux, 2017, p. 152; Serpell y Alarcón, 2017, p. 152. Como fuente de usos de la ingeniería y construcción en Chile, hemos revisado obras utilizadas en la enseñanza y en la práctica. Por todos, Arriagada (1988) 674 p.; pero también obras más recientes como De Solminihac y Thenoux (2017), 541 p., y Serpell y Alarcón (2017), 264 p.

${ }^{8}$ Arriagada, 1988, p. 323; De Solminihac y Thenoux, 2017, p. 151. 
costo directo 9 . Los materiales son costo directo en la medida en que quedan incorporados en la obra, incluido el costo de insumos requeridos para su incorporación ${ }^{10}$. Los equipos o maquinarias son costo directo en la medida en que están comprometidos directamente con toda o parte de la obra ${ }^{11}$.

La partida de costos directos incluiría seguros, fletes, derechos de internación (aranceles aduaneros), almacenaje, gestión de compra, depreciación del equipo, combustibles, mantención. La instalación e infraestructura de faena, el arriendo de equipos, los suministros de terreno y los subcontratos se consideran costos directos ${ }^{12}$. Cualquier costo que se pueda imputar, sin discusión, a una actividad o parte de la obra es costo directo de ella ${ }^{13}$. En definitiva, los costos directos pertenecen sin duda alguna a la categoría legal de costos de la obra, que incluye los materiales y el valor de los jornales ${ }^{14}$. Es decir, costos de la obra y valor de los jornales considerados como categorías jurídicas forman parte de la categoría técnica de costos directos.

\section{Los costos indirectos y gastos generales}

La ejecución de una obra tiene, para el que se obliga a ejecutarla, otra categoría de costos que se denominan indirectos. Se trata de gastos que ocurren en función de la obra (costos indirectos específicos) o se relacionan con la organización y actividad del contratista (costos indirectos generales). La suma de costos indirectos, incluidas las provisiones para contingencias, se denominaría gastos generales ${ }^{15}$.

Serían costos indirectos de la ejecución de un proyecto de construcción, por ejemplo: los costos de personal de administración y supervisión (gastos de personal, remuneraciones, bonos); los costos del personal de oficina de terreno (jefe administrativo, contador, administrativos, operadores de equipo de oficina, etcétera); el personal de ingeniería de terreno; el personal de compras, tráfico, bodegas; el personal de relaciones industriales (como asistentes sociales y auxiliares); el personal de seguridad; personal de porteros, cuidadores, serenos. Se incluyen en esta partida los costos de movilización del personal; los costos de arriendos y servicios relacionados con la administración y supervisión de la obra; los costos de instalaciones temporales (oficinas, lugares de acopio, talleres, comedores, cocinas, lugares de alojamiento del personal). Los costos indirectos incluyen también los costos de caminos de acceso, servicios de suministro, primas de seguros

\footnotetext{
${ }^{9}$ Arriagada, 1988, pp. 362-366.

10 Arriagada, 1988, pp. 413-426; Serpell y Alarcón, 2017, p. 48.

11 Arriagada, 1988, pp. 368-412; Serpell y Alarcón, 2017, p. 48.

12 Arriagada, 1988, p. 342; Serpell y Alarcón, 2017, p. 48.

13 De Solminihac y Thenoux, 2017, p. 151.

${ }^{14}$ Artículo 2003, regla $1^{\text {a }}$ CCch.

15 No existiría total unanimidad en torno a cuáles son costos indirectos y cuáles gastos generales.
} Los gastos generales se subdividirían en gastos del proyecto (que no se pueden imputar a una actividad o parte de la obra, específicamente) y gastos generales indirectos (costos financieros que permiten asegurar los pagos durante la ejecución de la obra, los costos de garantías, los gastos generales de la oficina central). De Solminihac y Thenoux (2017), p. 152. 
(daños a la propiedad; daños a terceros; todo riesgo de construcción; otros exigidos por el mandante). Estarían comprendidos en esta partida los costos financieros de boletas bancarias emitidas a nombre del que encarga la obra (seriedad de la propuesta, de ejecución de la obra).

Es frecuente que se asigne a esta partida una contribución a los gastos de la oficina central $^{16}$. El impuesto al valor agregado (I.V.A.) que el contratista es obligado a pagar por las compras de materiales, insumos y servicios afectos, y el impuesto único de segunda categoría son costos indirectos de la obra ${ }^{17}$. Las provisiones para contingencias pertenecen a los gastos generales de la obra, pero reciben distinto tratamiento según su forma de cálculo y destino final ${ }^{18}$.

\section{La utilidad o beneficio del contratista}

El precio del contrato incluye lo que se denomina beneficio, utilidad, ganancia o remuneración del contratista. En el campo de los proyectos de construcción, se entiende por utilidad el monto en dinero que el contratista estima que debería ganar por la ejecución del proyecto. El valor del trabajo o valor ganado (término tomado del uso de la industria) es igual al costo de materiales que han sido colocados, el costo de la mano de obra por colocarlos y todos los demás costos asociados hasta la fecha de control, incluyendo, utilidades y gastos generales del contratista ${ }^{19}$. Es decir, el resultado en dinero que el proponente tiene la expectativa de recibir para sí por la ejecución de una obra, descontados los costos directos e indirectos o gastos generales que ha supuesto su ejecución.

La utilidad o ganancia del contratista es una partida que se determina entre las partes según distintas modalidades. Una es la que consiste en una parte porcentual del valor de la obra, es decir, de todas las partidas anteriores (costos directos y gastos generales del contratista $)^{20}$. "Los gastos generales directos serán reembolsados. Los indirectos, pagados en base a porcentajes con respecto a los costos directos. La utilidad puede ser un porcentaje. Como alternativa es posible establecer sumas alzadas por concepto de gastos generales indirectos y utilidad, o porcentajes, fijos o decrecientes, con máximos asegurados" 21 . Por ejemplo, $5 \%$ u $8 \%$ de lo que, en la industria se denomina, el presupuesto ${ }^{22}$. Mediante esta modalidad, la utilidad o beneficio del contratista queda determinada cuando se perfecciona el contrato. Pero consiste en una suma variable, cuya

\footnotetext{
16 Arriagada, 1988, pp. 431-436; De Solminihac y Thenoux, 2017, pp. 151-152.

${ }^{17}$ De Solminihac y Thenoux, 2017, p. 152; Serpell y Alarcón, 2017, p. 48.

18 Arriagada, 1988, p. 440; De Solminihac y Thenoux, 2017, p. 152.

19 De Solminihac y Thenoux, 2017, p. 152; Serpell y Alarcón, 2017, p. 152.

${ }^{20}$ De Solminihac y Thenoux, 2017, p. 152.

21 Arriagada, 1988, p. 134.

${ }^{22}$ Cf. Artículo $4^{\circ}$, números 23) y 24) RCOP.
} 
fijación definitiva solo puede conocerse al final del contrato. Esto aparece reflejado en las normas que rigen la construcción de obras públicas ${ }^{23}$.

Otra forma de determinar la utilidad del contratista es la que considera como ganancia todo el excedente por sobre los costos directos y gastos generales ${ }^{24}$. Este excedente, que se reputa utilidad del contratista, se produce entre el "precio único prefijado" o "suma alzada” y lo que resulten ser los costos definitivos del contratista, directos e indirectos, según su mejor eficiencia en la gestión del tiempo y en la organización de los factores.

La utilidad o precio del contrato es siempre un valor bruto porque consiste en la ganancia antes de impuestos, tanto de la empresa como de sus dueños ${ }^{25}$. Por tanto, los impuestos a la renta del contratista no forman parte de los costos de una obra.

\section{Garantías, anticipos, estados de pago, retenciones y liquidación final}

Mientras la obra no tenga una aprobación definitiva, el uso exige al contratista el deber de garantizar el cumplimiento del contrato y la devolución del anticipo que recibe ${ }^{26}$ mediante boleta bancaria o póliza de seguro ${ }^{27}$. El mandante va proveyendo a cuenta del precio o por pagos provisorios, según el avance físico o proporcional de las obras, según estados de $\mathrm{pago}^{28}$. El estado de pago es una liquidación preliminar del avance físico o proporcional de la obra valorizado en términos monetarios, presentado periódicamente por el contratista al mandante. Incluye una liquidación provisoria de devoluciones del contratista al mandante (devoluciones del anticipo) y de retenciones del mandante al contratista (retenciones en garantía), según el plan de la obra, hasta la completa ejecución de los trabajos ${ }^{29}$. Las retenciones consisten en el derecho del mandante de suspender el pago de parte del precio, en cada estado de pago, hasta la aprobación definitiva de la obra, en garantía de la total y correcta ejecución de la obra ${ }^{30}$.

Los estados de pago se acompañan, según la naturaleza de los trabajos, de documentos que demuestren técnica y económicamente lo que en ellos se cobra, y de una factura que agrega el IVA (cuando corresponde). Una vez aprobados por el mandante,

${ }^{23}$ Cf. Artículo 76, número 2. RCOP. Por ejemplo, las variaciones o aumentos de obra pueden autorizarse por su costo directo, estimando los gastos generales y utilidad del contratista en un máximo del $30 \%$ de los costos directos (artículo 105, inciso $3^{\circ}$ RCOP).

${ }^{24}$ Arriagada, 1988, p. 324.

25 Arriagada, 1988, p. 324.

${ }^{26}$ Ex Artículo $2158,1^{\circ} \mathrm{CCch}$.

${ }^{27}$ Cf. artículos 96 y 98 RCOP.

${ }^{28}$ El uso de stage payments, schedules of values y pagos interinos es universal y transversal a toda modalidad de contratación. Ver: Bailey (2016a) 6.57; Hughes (2015), pp. 229-247; UfF (2013), pp. 269-270; Allensworth et al. (2009) 14.02; Baker et al. (2009) 4.131. El uso de un Schedule of Payments (calendario de pagos) que contempla un anticipo y pagos interinos durante la ejecución es común a todos los modelos FIDIC (Cláusula 14 y subcláusulas de todos los modelos).

29 De Solminihac y Thenoux, 2017, pp. 181-182; Serpell y Alarcón, 2017, p. 153.

30 Así, artículo 132 RCOP. Cf. Serpell y Alarcón, 2017, p. 153. 
los estados de pago son inmediatamente exigibles ${ }^{31}$; y se les atribuye consecuencias jurídicas específicas ${ }^{32}$. Sin embargo, todo pago se hace a cuenta del valor de la obra en ejecución ${ }^{33}$. Los estados de pago no pueden considerarse aprobación de la cantidad y calidad de la obra ejecutada ${ }^{34}$.

La recepción definitiva de la obra hace posible la liquidación final del contrato, donde se compensan los haberes y debes, y ambas partes se otorgan finiquito respecto de recíprocas acciones relativas a estas cuentas ${ }^{35}$. La normativa de obras públicas regula especialmente esta fase de una forma que refleja el uso de la industria ${ }^{36}$. En la liquidación final se registra la obra efectivamente ejecutada, su valor definitivo, y las devoluciones, retenciones y pagos provisorios efectuados por las partes. Se compensan los saldos a favor y en contra de las partes contratantes. El mandante devuelve las retenciones que todavía conserve en su poder. El mandante restituye la boleta bancaria o póliza de seguro constituida por el contratista en garantía del fiel cumplimiento del contrato.

El valor de los materiales, el valor de los jornales y la ganancia que el contratista tiene la expectativa de tener por la ejecución de la obra se presentan como partidas diferenciadas también normativamente. El valor de los materiales es mencionado en los artículos 2003 y 2005 del Código Civil chileno (CCch). En ellos se advierte que "valor de los materiales" es una suma diferente a "valor de los jornales" 37 . Se trata de dos de los varios ítems del todo llamado precio. El artículo 1999, inciso $2^{\circ}$ CCch distingue entre "todos los costos" del contratista (incluidos, desde luego, el valor de los materiales y el valor de los jornales), "lo que valga el trabajo hecho" y "lo que hubiere podido ganar en la obra”. Es decir, al momento de cesación unilateral del contrato de obra, el trabajo hecho (remuneración del contratista) tendría un valor, que sería distinto al de los costos (valor de los materiales, valor de los jornales y todo otro costo). Por la cesación unilateral del contrato, el mandante debe pagar, además, lo que el contratista hubiere podido ganar con la obra ${ }^{38}$.

Todos estos factores como asimismo los usos de la industria acerca de la forma de pago del precio, sirven de presupuestos de hecho para la operación jurídica en que consiste la determinación del precio, cuestión a la que nos referimos a continuación.

31 Según Serpell y Alarcón (2017), p. 153, en la práctica se pagan a 30 o 60 días.

${ }^{32}$ Por ejemplo, prueba de que el contratista ha ejecutado un determinado volumen, porcentaje o unidades de obra y que ha incurrido en costos y gastos que tiene derecho a cobrar al mandante. Así, MolinA Y Ríos (2017), p. 172.

33 Para obras públicas, lo disponen expresamente el artículo 154 RCOP; y el artículo 115 DTO-236.

34 Así lo dispone, por ejemplo, el artículo 115 DTO-236.

${ }^{35}$ Cf. artículo 184 RCOP y artículo 130 DTO-236.

36 Artículo 177 RCOP.

37 Artículo 2003, $1^{\circ} \mathrm{CCch}$.

${ }^{38}$ Lo que el contratista hubiere podido ganar por la obra sería su interés positivo en el contrato, independientemente de los costos y gastos (interés negativo). Contardo, 2011, pp. 85-118. Véase también, ERbetTA, 2017, pp. 9-51. 


\section{Determinación Del PRECiO}

Jurídicamente, el precio se determina mediante pactos o convenciones. Los pactos concernientes al precio del contrato consisten en la forma cómo las partes acuerdan estimar los costos (directos e indirectos) de la ejecución de la obra y la utilidad del contratista ${ }^{39}$. La propuesta técnica y económica del contratista según la obra descrita en los planos y especificaciones aceptada por el mandante determina el precio pactado entre las partes; es decir, el "precio del contrato" 40 . En el campo de las obras públicas, esto se produce mediante el acto de adjudicación ${ }^{41}$. Sin embargo, el precio queda fijo e invariable una vez reconocida y aceptada la obra por el mandante ${ }^{42}$, y recibida definitivamente por la autoridad competente ${ }^{43}$.

En este contexto, las convenciones más comunes en el precio en el contrato de construcción son: el precio por costos y beneficios, el precio por cantidad o medida más beneficio; y el precio único prefijado o suma alzada. "Si no se ha fijado un precio", agrega el Código Civil chileno, "se presume que las partes han convenido en el que ordinariamente se paga por la misma especie de obra, y a falta de este por el que se estimare equitativo a juicio de peritos" ${ }^{44}$.

A continuación una aproximación a las formas de determinación del precio que no parecen pretender la total invariabilidad. El epígrafe que sigue se refiere a la cláusula especial de suma alzada o precio único prefijado.

\section{Precio pactado por costos más beneficio}

El precio por costos consiste en la aceptación del mandante al presupuesto presentado por el contratista para la ejecución de una obra, conforme con los planos y especificaciones proporcionados por él en la invitación a presentar ofertas. En el presupuesto, el contratista estima sus costos directos, indirectos, gastos generales y la utilidad o ganancia suya.

Para la eficaz ejecución de este contrato, el contratista está obligado a llevar registro documentado, cuidadoso y ordenado de sus costos. El contratista está obligado a mantener al día y exhibir sus registros a requerimiento del mandante. La utilidad del contratista es un porcentaje de los costos o una suma fija, previamente convenida y

${ }^{39}$ Cf. artículos 1999 y 2005 CCch; artículo 76 RCOP. Lo anterior debería ser relacionado con el artículo 2158 CCch, norma conectada con el contrato de construcción por remisión expresa del artículo 2012 CCch. Este último considera que los servicios "de las profesiones y carreras que suponen largos estudios" (artículo 2118 CCch), como los de arquitectos, ingenieros y constructores son servicios inmateriales que se sujetan también a las reglas del mandato. El que encarga la obra (sea o no el dueño de ella) es un mandante o comitente.

${ }^{40}$ Molina y Ríos, 2016, p. 164; Prat, 1940, pp. 31 y 46.

41 Artículos 86 y 108 RCOP.

42 Artículo 2000 CCch; artículo 166 RCOP.

43 Artículo 144 LGUC.

${ }^{4}$ Artículo 1997 CCch. "La donación entre vivos no se presume" (artículo 1393 CCch; cf. artículo 2299 CCch). El contrato de construcción es oneroso, no aleatorio (exartículo 1441 CCch; artículo 1915 CCch). Cf. Dig. 19.2.20.1 (Paulus 34 ad ed.): No puede celebrarse arrendamiento por causa de donación. 
prevista en el presupuesto. El mandante provee o reembolsa los costos de la ejecución, según la periodicidad pactada, mediante el sistema de estados de pago. El beneficio del contratista se paga según el avance de la ejecución, como un porcentaje de los costos o una suma fija predeterminada, todo sujeto a la liquidación final del contrato ${ }^{45}$.

La convención acerca del precio del contrato podría ser, esencialmente, un pacto respecto del valor del trabajo o industria del contratista, la razonable remuneración de su experiencia en la organización y dirección de la ejecución de un proyecto. Esto está reconocido explícitamente en numerosas legislaciones ${ }^{46}$. El Código Civil chileno reconoce indirectamente este pacto en el artículo 1996 CCch. Ahí se dice que si el artífice suministra la materia, el contrato es de venta; salvo que "la materia principal", como el terreno donde se edifica o construye, "sea suministrada por el que ha ordenado la obra, poniendo el artífice lo demás”, como los materiales y mano de obra. Es decir, el contrato que consiste en la ejecución de una obra sobre un inmueble (la materia principal) es siempre un arrendamiento de servicios para la ejecución de una obra, no es venta ${ }^{47}$. El contrato de construcción puede perfeccionarse igualmente por la ejecución de una obra con materiales y mano de obra proporcionados por el dueño o mandante, o por el contratista. Si los materiales y mano de obra son proporcionados por el dueño o por el mandante, el precio del contrato será exclusivamente la utilidad o ganancia del contratista. Si el contratista se obliga a proporcionar materiales y mano de obra, el precio del contrato incluirá estos costos como también la utilidad o ganancia del contratista.

La ejecución de una obra por costos más beneficio sería la forma básica del contrato de construcción. Los costos son del mandante, pues quedan agregados al sitio de las obras o a lo edificado en él. El beneficio o utilidad es la remuneración del contratista por su experiencia en la organización de todos los factores que conducen a la ejecución de una obra proyectada, según el estado del arte ${ }^{48}$.

\section{Precio pactado por cantidad o medida más beneficio}

El precio de un contrato por cantidad o medida consiste en la estimación del contratista aceptada por el mandante de los costos, directos e indirectos, y de su utilidad, por cada unidad o medida de obra, conforme con los planos y especificaciones proporcionados por el mandante. Si el contratista propuso ejecutar la obra a un precio por medida o por unidad, el precio se determina según esa medida y cantidad ${ }^{49}$. Esto exige

45 Arriagada, 1988, p. 134.

${ }^{46}$ El artículo 1787 del Código Civil francés, todavía dispone: "Puede contratarse la ejecución de una obra, conviniendo en que el que la ejecute ponga solamente su trabajo o su industria, o que también provea el material". Norma procedente del texto original promulgado en 1804 . Tiene norma homóloga en el artículo 1588 del Código Civil español de 1889; y en García Goyena, 1852, Tomo III, p. 481 (artículo 1529).

47 SAN MARTín, 2016, p. 171.

${ }^{48}$ El uso denomina este pacto Cost Plus. El contratista se obliga a ejecutar la obra por su costo más un margen o suma de utilidad. BAILEy (2016a) Vol. I, pp. 6.10.

49 "Los precios unitarios se entenderán inamovibles y las cubicaciones se ajustarán a las obras efectivamente realizadas, verificadas por [el mandante] de acuerdo a los documentos de licitación” (artículo $4^{\circ}, 31$ ) RCOP). 
la comprobación de medidas (remeasurements) por parte del dueño o de su representante antes de la autorización de los estados de pago presentados por el contratista ${ }^{50}$.

Se asegura que los pactos de precio por costos o por unidad o medida garantizan un precio más bajo para el mandante, evitando las provisiones (inciertas y hacia el alza) que debe hacer el proponente si el contrato es por una suma fija ${ }^{51}$. Esta forma de determinación del precio puede ir acompañada de otro pacto, por el que el mandante fija la cuantía del contrato en un monto máximo. Este pacto se denomina precio máximo garantizado. Por el pacto de precio máximo garantizado, el contratista se obliga a ejecutar la obra y el mandante a pagarla por su costo, por unidad o cantidad, pero hasta un monto máximo, que opera como tope garantizado tanto para el mandante como para el contratista ${ }^{52}$. El mejor desempeño del contratista le asegura una mejor utilidad o beneficio en la ejecución de la obra. La tercera forma más frecuente de determinar el precio es mediante una cláusula especial de precio único prefijado.

\section{Contraprestación según lo que sea usual}

En el ámbito anglosajón existe referencia al precio quantum meruit según el contrato. El precio se entiende pactado quantum meruit cuando el mandante acepta una propuesta del contratista para ejecutar una obra por lo que sea razonable ${ }^{53}$. Interesa observar que los costos y gastos en que haya debido incurrir el contratista para ejecutar el encargo son de cargo del mandante; y que este se obliga a pagar "la remuneración estipulada o usual" 54 .

\section{Cláusula de suma AlZada E INVARIABILIDAD DEL PRECiO}

El pacto de precio único prefijado o suma alzada consiste en la obligación que asume el empresario que se obliga a ejecutar toda la obra de no pedir aumento de precio por alzas en el costo de insumos, por modificaciones no ordenadas ni autorizadas por el mandante ${ }^{55}$, o por circunstancias previstas o posibles de prever ${ }^{56}$. Según el Código Civil, esta cláusula tiene unos determinados requisitos y produce ciertos efectos en la

${ }^{50}$ Los modelos FIDIC RED BOOK (1999) (Cláusula 14), como también el modelo FIDIC MDB (Multilaretal Development Banks), operan según fórmulas de determinación del precio por procesos de validación de medidas. BAKer et al. (2009) 4.20; 4.3. Sobre estos contratos, Figueroa (2013), pp. 7-24.

51 BAKER et al., 2009, 4.20.

52 El artículo $\left.4^{\circ}, 30\right)$ RCOP asume implícitamente que la propuesta por suma alzada puede considerar partidas por precios unitarios, de manera que el valor total del contrato corresponda a la suma de las partidas fijas y las partidas por precios unitarios.

53 Bailey, 2016a, 6.14.

${ }^{54}$ Artículo 2158 CCch. Cf. artículos 1441, 1915, 1997 CCch. Cf. Dig. 19.2.20.1 (Paulus 34 ad ed.) No puede celebrarse arrendamiento por causa de donación.

55 Artículo 2003, regla $1^{\text {a }}$ CCch.

56 Artículo 2003, regla $2^{\text {a }}$ CCch. 
estabilidad del "precio del contrato". No garantizaría la total invariabilidad. Se examinan estos aspectos a continuación.

\section{Requisitos de la cláusula especial de suma alzada}

Los requisitos que se reconoce que debe reunir esta cláusula son tres. Primero, el pacto debe referirse a "contratos para construcción de edificios, celebrados con un empresario que se encarga de toda la obra" 57 . La presencia de un empresario de la construcción "que se encarga de toda la obra" exige un contratista general que trabaja con subcontratistas $^{58}$. El contratista general es un empresario que trabaja con especialidades de la construcción que pueden ejecutarse directamente, o cometerse a subcontratistas ${ }^{59}$. La calidad de empresario supone la presencia de una persona natural o jurídica que obliga su experiencia y capacidad en la organización de recursos y de trabajo ${ }^{60}$, para ejecutar "toda la obra" y no solo partes de ella.

Segundo, el pacto solo puede hacerse respecto de un proyecto completamente trazado, en todos sus niveles, conceptual y de detalle; completo y definitivo, no sujeto a cambios ${ }^{61}$. Las órdenes de cambio durante la ejecución de las obras alteran el precio único por mutuo acuerdo entre las partes. El mandante no puede negarse a pagar el mayor valor que estos cambios produzcan en los costos de ejecución de la obra total, incluidos los costos indirectos ${ }^{62}$. Por este motivo es que se ha decidido que la suma alzada no obliga si, para ejecutar las obras, el contratista debe asumir obligaciones que corresponderían al mandante, como confeccionar planos y realizar obras adicionales para cumplir exigencias del proveedor de servicios sanitarios, que "no pueden ser consideradas como parte de los riesgos tomados al celebrar la convención”63. El contratista no está obligado a realizar obras adicionales, no consideradas en un proyecto adjudicado a precio único ${ }^{64}$. Aunque parezca evidente, todas las modificaciones de obra ordenadas

${ }^{57}$ Artículo 2003 pr CCch.

58 Molina y Ríos, 2016, p. 219; PodetTi, 2004, p. 84. En este sentido, la expresión contratista general difiere de la figura del General Contractor de un contrato EPC. Molina y Ríos (2016), p. 81.

59 Con relación al IVA, el hecho gravado con el impuesto es, para la autoridad fiscal, el contrato general de construcción en todos los casos en que la obra incluye dos o más especialidades, y no se ejecuta por administración delegada (D.S. N ${ }^{\circ} 55$, de Hacienda, de 1977, modificado por el D.S. N 682, de Hacienda, publicado el 8 de febrero de 2018). El IVA es un impuesto a las ventas y servicios gravados.

${ }^{60}$ Podetti, 2004, p. 78.

${ }^{61}$ Molina y Ríos, 2016, p. 50. Este principio rige también en el campo de las obras públicas. En este sentido, Contraloría General de la República, Dictamen N ${ }^{\circ}$ 25962, de 7 de mayo de 2012, y sus antecedentes.

${ }^{62}$ Así se resolvió en OHL CON FISCO (2016).

63 Constructora monteverde con Municipalidad de La Ligua (2013).

${ }^{64}$ OBRAS ESPECIALES CON SERVIU DEL Bío Bío (2017). Según la normativa el proponente no está obligado a considerar en su oferta la ejecución de partidas adicionales (artículo $5^{\circ}$ D.S. N N $^{\circ} 236$, de 2003). La falta de definición y planificación de los proyectos, la falta de claridad respecto del alcance de los trabajos en los procesos de licitación es una dificultad referida por la industria. BACigalupo (2006), pp. 20-21. VIAL y MackenNa (2005), p. 23. 
por el mandante y aceptadas por el contratista deben ser pagadas. Por tanto, modifican el precio del contrato.

El tercer requisito es que se pacte un precio "global, invariable, fijado de antemano" 65. Un precio global por la edificación de "toda la obra”, incluidas todas sus partes. El precio único por toda la obra es distinto al precio por partes o por unidades de medida. Si estas partes o medidas parciales de la obra total exigen revisión para su aprobación parcial o total, podríamos no estar exactamente en un contrato por precio único o suma alzada. El pacto sería de precio por unidades o partes de la obra, o por medidas de obra. Los contratos deben interpretarse de acuerdo con lo que las partes han pactado, no por el nombre o "modalidad de contratación" que han elegido para consignar en los documentos.

\section{Efectos según sus antecedentes históricos}

La cláusula especial de suma alzada no garantizaría la total invariabilidad del precio ${ }^{66}$. Sin embargo, se difiere respecto de las razones por las que debería admitirse la revisión del precio ${ }^{67}$. En este trabajo defendemos la idea de que los antecedentes históricos y el sentido mismo de las reglas $1^{\mathrm{a}}$ y $2^{\mathrm{a}}$ del artículo 2003 corroborarían la apreciación de que el pacto de suma alzada tiene limitaciones intrínsecas ${ }^{68}$ : las variaciones de obra ordenadas por el mandante y aceptadas por el contratista, y las circunstancias extraordinarias que no ha sido posible prever al tiempo del contrato. Excluidas estas dos variables, la cláusula de precio único prefijado tiene toda su fuerza en lo que se refiere a alzas de precios de insumos del contratista (materiales, maquinaria, mano de obra).

La regla $1^{\text {a }}$ del artículo 2003 tiene una lectura pacífica en este sentido: el empresario que se obligó a la ejecución "de toda la obra por un precio único prefijado" "no podrá pedir aumento de precio, a pretexto de haber encarecido los jornales o los materiales". Es decir, el valor de los materiales como también el de los jornales (horas hombre) forma parte de la previsión ordinaria del empresario, que es un experto en la edificación. Las variaciones en estas partidas son un riesgo de desempeño, que está dentro de la razonable previsibilidad de su experiencia. Las variaciones de precio de insumos no son admisibles si se ha pactado precio único prefijado.

${ }^{65}$ Meza Barros, 2004, Tomo I, p. 459.

66 Albornoz, 2011, 397-415; Southerland, 2014, pp. 161-195.

${ }^{67}$ La contratación estaría en cláusulas rebus sic stantibus, en función de la buena fe con que deberían ejecutarse los contratos. Del Arco y Pons (2010), pp. 115-128. La revisión de estos pactos, se afirma, sería más compleja en obras civiles que en obras públicas. Del ArCo y Pons (2010), pp. 129-148. En sentido semejante, Podetti, 2004, p. 64; y Fleischmann y León, 2017, pp. 96-97.

${ }^{68}$ Las reglas $1^{\text {a }}$ y $2^{\text {a }}$ del artículo 2003 CCch proceden de los artículos 54, 55 y 57 del Párrafo $8^{\circ}$ del Título XXV, del Proyecto De i 842. La redacción se mantiene inalterada en los artículos 459 y 460 del Proyecto de i 847; en los artículos 2195 y 2196 del Proyecto de i 853; y en el artículo 2177 letra h del Proyecto Inédito. Según notas puestas por el redactor del Código Civil al artículo 2195 del ProyeCto DE I 853, el artículo 2003 CCch, regla 1ª , procede del artículo 1793 del Código francés; no hay noticia relativa a la regla $2^{a}$. Ahí aparece una referencia a Delvincourt (1827) Tomo III, p. 118. El pasaje se encuentra, casi literalmente, en la página 275 del Tomo Séptimo, lugar donde el autor comenta el artículo 1793 del Código Civil francés. 
Este criterio cambia cuando se trata de variaciones al plan primitivo de la obra. El empresario que se obligó a la ejecución "de toda la obra por un precio único prefijado" "no podrá pedir aumento de precio, a pretexto de [...] haberse hecho agregaciones o modificaciones en el plan primitivo, salvo que se haya ajustado un precio particular por dichas agregaciones o modificaciones". Para que el contratista pueda pedir aumento de precio por modificaciones o agregaciones, estas deben estar autorizadas expresa o tácitamente por el mandante ${ }^{69}$. Dicho de otro modo, las órdenes de cambio del mandante aceptadas por el contratista modifican el contrato. El contratista no puede hacer agregaciones o modificaciones al plan primitivo sin contar con la autorización del mandante, "salvo que se haya ajustado un precio particular por dichas agregaciones o modificaciones". Dicho "precio particular" puede ajustarse al momento de perfeccionarse el contrato. Pero también puede convenirse al momento de aceptar la ejecución de agregaciones o modificaciones. Recientemente se ha resuelto que las modificaciones convenidas entre mandante y contratista que impactan el itinerario de ejecución de los trabajos, modifican el precio del contrato, y el mandante debe pagar al contratista los costos indirectos causados por dichos cambios ${ }^{70}$. Las variaciones de precio por agregaciones o modificaciones son, en definitiva, del cargo del mandante. El contratista puede pedir su pago incluso forzadamente.

La regla $2^{\text {a }}$ del artículo 2003, en cambio, parece más oscura: "Si circunstancias desconocidas, como un vicio oculto del suelo, ocasionaren costos que no pudieron preverse deberá el empresario hacerse autorizar para ellos por el dueño, y si este los rehúsa, podrá ocurrir al juez para que decida si ha debido o no preverse el recargo de obra, y fije el aumento de precio que por esta razón corresponda"71. La regla refleja cargas de colaboración entre las partes: el empresario debe hacerse autorizar por el dueño para afrontar estos eventos. Pero si el dueño se niega, el empresario podrá ocurrir al juez para que resuelva respecto de la previsibilidad del evento y la cuantía de lo que debe pagar el mandante. Es decir, son de cargo del dueño los eventos que no han podido preverse. Estos se traducen en un "aumento de precio" que, a falta de acuerdo entre las partes, se determina judicialmente.

La clave para entender a qué circunstancias pudo haberse referido el redactor del Código Civil chileno en la regla $2^{\mathrm{a}}$ del artículo 2003 podría estar en un ejemplo puesto por Pothier al artículo 1793 del Código Civil francés. El ejemplo es el siguiente: si teniendo que levantar un edificio en un terreno que se creía de tierra sólida, se hubiesen después encontrado antiguas excavaciones que hubieren acarreado mucho más trabajo y nuevas obras para levantar los cimientos, el dueño deberá pagar ese aumento; y si sostiene que esas obras no eran necesarias, el juez sujetará esta cuestión a peritos, para que regulen el precio del aumento de las obras y su necesidad ${ }^{72}$.

${ }^{69}$ El artículo 2003, regla $1^{\text {a }}$ CCch no exige autorización escrita del mandante para la realización de estas obras, a diferencia de su antecedente en el Código Civil francés.

${ }^{70}$ OHL CON FISCO (2016).
${ }^{71}$ Artículo 2003, regla $2^{\text {a }}$ CCch.
${ }^{72}$ Pothier, 1788, p. 363. 
Es decir, el precio único prefijado incluye todo lo que según una eficiente previsión puede e incluso debe preverse entre los costos necesarios para ejecutar una obra: aumentos de costo de materiales y otros insumos, como jornales. No se incluyen modificaciones al proyecto ordenadas por el mandante. No se incluyen circunstancias que fueron imposibles de prever al tiempo del contrato y que han hecho más onerosos los trabajos. El pago de estos costos exige, parece ser, la carga de comunicarlos al mandante, y "hacerse autorizar para ellos por el dueño”. El incumplimiento de esta carga de comunicación puede producir la inoponibilidad del evento al dueño, que no pudo haber autorizado lo que no pudo haber conocido ${ }^{73}$.

\section{LAS CONSECUENCIAS DE Distintos EVENTOS EN EL PRECIO}

El pacto de precio único prefijado y otras convenciones en el precio se comportan de modo distinto frente a un número de eventos que hemos agrupado en cuatro categorías: el aumento en el precio de insumos, las variaciones de obra u órdenes de cambio, la subsanación de defectos o fallas de construcción y el acaecimiento de circunstancias imposibles de prever. A continuación se examina el efecto de los distintos pactos frente a cada uno de estos eventos.

\section{Aumentos en el precio de insumos}

Por el pacto de costos más beneficio el mandante asume las variaciones que experimenten los precios de insumos del contratista (materiales, maquinaria, mano de obra). El mandante también asume los costos operacionales del contratista. El beneficio del contratista es una parte o cuota de los costos; a menos que se pacte expresamente que este beneficio es una parte o cuota del precio estimado al principio del contrato (o valor presupuestado). Este pacto exige un control intenso del mandante (o sus representantes) durante la ejecución de la obra; pero es menos oneroso para el mandante si se considera que no paga sumas alzadas que pueden no responder a costos reales.

El pacto de un precio por cantidad o unidad de obra mitiga el riesgo de variaciones en el precio que puede experimentar el mandante. El beneficio del contratista se paga según lo pactado por cantidad o unidad. En consecuencia, el alza en el precio de insumos es un riesgo del contratista.

Es el mismo efecto que produce el pacto de suma alzada, en que el contratista no puede pedir aumento de precio por haberle subido el precio de materiales o mano de obra $^{74}$. Los aumentos de precio de insumos que derivan de cambio de normativa de

73 En este sentido, Rodríguez, 2017, pp. 321-340; Rodríguez, 2018, pp. 455-482.

${ }^{74}$ Artículo 2003, regla $1^{\text {a }}$ CCch. Según pactos de fixed price (precio prefijado) cualquier ahorro en las partidas del precio estimado es a beneficio del contratista. Como contrapartida, si la ejecución de la obra supone costos y gastos superiores al estimado, la diferencia es una pérdida del contratista. Hughes (2015), p. 99. 
autoridad pueden quedar excluidos de la previsibilidad del contratista. Esto también se considera en obras públicas ${ }^{75}$.

Puede concluirse que los aumentos en el precio de insumos para la ejecución de la obra son un riesgo que las partes pueden atribuir al contratista mediante cláusulas de precio por unidad o cantidad de obra, o de precio único prefijado. No ocurre lo mismo con las variaciones de obra.

\section{Variaciones de obra u órdenes de cambio}

Las variaciones de obra modifican el contrato pues son órdenes de cambio del mandante aceptadas expresa o tácitamente por el contratista. Modifican el objeto del contrato, lo que la ingeniería denomina el alcance de los trabajos; modifican también el precio pactado y, según su envergadura, el itinerario de obras ${ }^{76}$. Son de cargo del mandante los mayores costos que deba soportar el contratista por estos cambios. Por otra parte, el contratista tiene derecho a la remuneración o beneficio proporcional por estas obras.

El mismo resultado se aplica al pacto de precio único prefijado. Las obras extraordinarias o trabajos suplementarios al proyecto original modifican el contrato; modifican también el precio único prefijado cuando han sido ordenadas o autorizadas por el mandante. El derecho chileno no exige que estas órdenes consten por escrito ${ }^{77}$. Aunque es evidente que pesa sobre el contratista la carga de pedir autorización para la ejecución de trabajos no previstos en el plan original de la obra, y llevar registro de estas modificaciones para su posterior cobro $^{78}$. Por esto es que se ha resuelto que la suma alzada no incluye gastos generales que el contratista se ha visto obligado a soportar por el impacto de modificaciones al proyecto ordenadas o autorizadas por el mandante en la ruta crítica de los trabajos ${ }^{79}$.

75 Artículo 109 RCOP.

76 En el mismo sentido, Fleischmann y León, 2017, p. 97.

77 El Código Civil francés actualmente vigente mantiene el artículo 1793 en su texto original. Ahí se lee lo siguiente: "Artículo 1793. En aquellos casos en que un arquitecto o contratista se encarguen por un ajuste alzado de la construcción de un edificio de acuerdo con un plano establecido y convenido con el propietario del suelo, no podrán solicitar ningún aumento de precio alegando ni un incremento de la mano de obra o los materiales, ni los cambios o aumentos realizados sobre el plano, a menos que dichos cambios o aumentos hubiesen sido autorizados por escrito y el precio acordado con el propietario".

${ }^{78}$ Se ha resuelto que la suma alzada no incluye obras realizadas por el contratista con la aquiescencia tácita del mandante; la aquiescencia tácita es aprobación. CAM Santiago, 22.11.2004, rol 364-2004; no incluye los mayores costos derivados de la facultad que el mandante se reserva, en un contrato EPC por precio fijo, de introducir modificaciones "toda vez que lo estime necesario". CAM Santiago, 29.7.2010, rol 1087-2010.

${ }^{79}$ OHL CON FISCO (2016). El contratista, efectivamente, asume el riesgo de un mayor valor de la obra por variaciones en las partidas presupuestadas. Por ejemplo, "por un aumento de precios de los materiales, equipos o mano de obra” (C. Vigésimo noveno). Este pacto no consiste en que el contratista deba asumir "gastos extraordinarios que provengan de las condiciones diferentes en que debió ejecutarse la obra, como consecuencia de la alteración sustancial de la secuencia constructiva, originada por las modificaciones que el [Ministerio de Obras Públicas] ordenó para solucionar inconsistencias y errores de que adolecía la obra diseñada exclusivamente por él” (C. Vigésimo noveno). 


\section{Subsanación de defectos o fallas de construcción}

Las obras que responden a la subsanación de defectos o fallas de construcción son, en cambio, de cargo del contratista, aunque las ordene el mandante o la autoridad para reconocer y aprobar definitivamente la obra. Los defectos o fallas de construcción pertenecen al riesgo de desempeño del contratista. La reparación de fallas o defectos de construcción pertenece, por tanto, a la obligación del contratista antes de aprobada la obra $^{80}$. La responsabilidad del contratista subsiste incluso hasta después de aprobada y recibida definitivamente la obra, aunque la ley atribuya responsabilidad por los daños causados por fallas o defectos al dueño. El dueño siempre puede repetir contra el contratista $^{81}$. Tiene lógica que se haya resuelto que un pacto de suma alzada no incluye los mayores costos que procedan de la reparación o reposición de obras defectuosas ${ }^{82}$.

\section{Circunstancias imprevistas ajenas a toda anticipación}

La cuestión más compleja parece ser las consecuencias de eventos sobrevinientes, no previstos y que no era posible prever al tiempo del contrato; es decir, el caso "extraordinario y ajeno a toda previsión" 83 . Pertenece a la razonable diligencia del contratista la previsión de contingencias antes y durante la ejecución del contrato. Así se concluye de la condición que establece el artículo 2003, regla $2^{a}$ CCch: el juez interviene para resolver "si ha debido o no preverse el recargo de obra" y para fijar "el aumento de precio que por esta razón corresponda". El aumento de precio que proceda por costos "que no pudieron preverse" en el precio único prefijado, como "un vicio oculto del suelo", es de cargo del mandante.

Entre las circunstancias desconocidas e imposibles de prever al tiempo del contrato podrían encontrarse algunos actos de autoridad. La póliza a todo riesgo de construcción generalmente excluye de cobertura los siguientes eventos: actividades u operaciones de guerra declarada, invasiones, revolución, rebelión, insurrección, conmoción civil, motines, conspiraciones; reacciones nucleares, radiación o contaminación radiactiva ${ }^{84}$.

La nómina de estos riesgos es abierta. Los modelos FIDIC, por ejemplo, consideran que los riesgos imprevisibles incluyen, entre otros: condiciones climáticas o físicas excepcionalmente adversas; decisiones políticas; imprevista escasez de insumos por

${ }^{80}$ Artículos 2000, 2001, 2002 CCch.

81 Artículos 2003, regla 3a y 2324 CCch. Artículos 18 y 19 LGUC. Sobre esta materia, CorraL (2013), pp. 275-279.

${ }^{82} \mathrm{La}$ materia que se discute en CODELCO CON CONSORCIO CONSTRUCTORA ARANEDA BRAIN (2015) son defectos constructivos que la demandada alega ser imputables a defectos de diseño e ingeniería, responsabilidad del mandante. CAM SANTIAGO, 9.3.2006, rol 461-2006; CAM SANTIAGO, 18.7.2005, rol 444-2005.

${ }^{83}$ Cf. artículo 150 RCOP. Sobre esta materia en la práctica, Ríos, 2017, pp. 215-229.

${ }^{84}$ Artículo 12 de la Póliza de seguro para todo riesgo de construcción, incorporada al Depósito DE Pólizas bajo el código POL 12014114 (Mapfre Compañía de Seguros Generales de Chile S.A). Sobre esta póliza en la construcción, Molina y Ríos (2016), pp. 288-301. Sobre la póliza Contractor's All Risks (Todo riesgo del contratista), cf. BunNi (2003) pp. 398-407. 
epidemia u actos de autoridad; descubrimientos arqueológicos; fuerza mayor; insolvencia del contratista ${ }^{85}$. En la Cláusula 19.1 de los modelos FIDIC, se consideran los siguientes eventos: (a) guerra, hostilidades, invasión de enemigos; (b) rebelión, terrorismo, revolución, insurrección, golpes de Estado, o guerra civil dentro del país; (c) revueltas, conmoción o desorden interior en el país; (d) huelga o paralización de faenas del personal del contratista y subcontratistas; (e) municiones de guerra, explosivos, radiación o contaminación por radiactividad; y (f) terremoto, huracán, tifón o actividad volcánica imposible de prever y contra los que un contratista con experiencia no habría podido tomar medidas preventivas ${ }^{86}$.

Los riesgos imprevisibles serían también los que, en el ámbito de la construcción, no tienen cobertura por la industria del seguro ${ }^{87}$. Los mayores costos que provengan del caso extraordinario ajeno a toda previsión no podrían atribuirse al contratista. Son riesgos que corresponden al dueño cualquiera sea el precio pactado entre las partes para ejecutar la obra.

\section{Conclusiones}

El precio del contrato de construcción es un todo que incluye costos directos, costos indirectos y gastos generales del contratista, como asimismo la utilidad o beneficio que se ha pactado por su trabajo, o lo que es usual pagar por él. Estos factores técnicos y económicos se integran en las convenciones más comunes por las que se determina el precio del contrato: precio por costos más beneficio, precio por cantidad o unidad de obra más beneficio, precio único prefijado o cláusula especial de suma alzada. El precio inicial o precio del contrato es una estimación del precio de la obra, que solo queda definitivamente fijo e invariable con la aprobación y recepción definitiva. La variabilidad del precio se constata en el comportamiento de los diversos pactos en precio frente a los hechos que más frecuentemente producen variaciones: el alza de precios de insumos para la ejecución de la obra; las variaciones de obra u órdenes de cambio del mandante; la subsanación de defectos o fallas de construcción; y, por último, las circunstancias extraordinarias imposibles de prever al quedar convenidas las partes en la ejecución de la obra y en el precio.

La razonable previsibilidad del contratista puede anticipar las variaciones de precios de insumos e incorporar este factor en su estimación inicial, pactando un precio por cantidad o unidad de obra o un precio único por toda la obra. Estos pactos, sin embargo, no impiden las variaciones que se producen por modificaciones al proyecto durante su ejecución, ordenadas por el mandante y aceptadas por el contratista. Estas variaciones modifican el contrato. Por tanto, modifican el precio y, según su envergadura, el plazo

\footnotetext{
85 Fidic Procurement Procedures Guide (2011), p. 34.

${ }^{86}$ Por todos, cf. Fidic Red book (1999), Clause 19.1. Cf. KLEE (2015), pp. 354-371.

${ }^{87}$ Cf. Baeza Pinto (2001), pp. 69-94; Contreras Strauch (2014), p. 209.
} 
de ejecución de los trabajos. Modifican también, proporcionalmente, la utilidad del contratista, salvo pacto en contrario. Los mayores costos por subsanación de defectos o fallas de construcción durante la ejecución de la obra o después de su aprobación pero antes de su recepción definitiva son exclusivamente de cargo del contratista. Las circunstancias extraordinarias imposibles de anticipar son de cargo del mandante.

\section{BIBLIOGRAFÍA}

Albornoz Pollmann, Laura (2011): "Contrato de ejecución de obra a suma alzada: ¿Cuál es la vigencia y real aplicación del supuesto de invariabilidad que se contiene en el artículo 2003 C.C.", en Corral, Hernán, Estudios de Derecho Civil. Contratos, Tomo III (Santiago, Chile, Legal Publishing Chile), pp. 397-415.

Arriagada, Gustavo (1988): Administración integral de proyectos (Santiago, Chile, Colegio de Ingenieros de Chile A.G.), 674 p.

Allensworth, W., Ross, Altman J., Overcash, A., and Patterson, Carol J. (ed.) (2009): Construction Law (Chicago, IL: ABA Book Publishing) 782 p. (referencias a los párrafos numerados de la edición electrónica).

Bacigalupo, Dante (2006): Diagnóstico de la relación mandante contratista. Efectos de la situación actual (Santiago, Chile, Corporación de Desarrollo Tecnológico de la Cámara Chilena de la Construcción) 22 p. Disponible en: http://biblioteca.cchc.cl/DataFiles/18808.pdf Fecha de consulta: 26 de enero de 2018).

Baeza Pinto, Sergio (2001): El seguro (Edición actualizada por Juan Achurra Larraín y Juan José Vives Rojas, Santiago, Chile, Editorial Jurídica de Chile) 511 pp.

BAILEY, Julian (2016a): Construction Law, Volume I, Second Edition (New York, NY: Informa Law) 1049 p. (referencias a los párrafos numerados de la edición electrónica).

BaILEY, Julian (2016b): Construction Law, Volume II, Second Edition, New York, NY: Informa Law. (referencias a los párrafos numerados de la edición electrónica).

Baker, Ellis; Mallors, Ben; Chalmers, Scott; Lavers, Anthony (2009): FIDIC Contracts: Law and Practice (London, Informa Law) 624 p. (referencias a los párrafos numerados de la edición electrónica).

Bunni, Nael G. (2003): Risk and Insurance in Construction (New York, New York, Spon Press) 471 p.

Contardo, Juan Ignacio (2011): "Los criterios de interés contractual positivo y negativo en la indemnización de perjuicios derivada de resolución contractual”, Revista de Derecho Universidad Católica del Norte, Año 18, No 1, pp. 85-118.

Contreras Strauch, Osvaldo (2017): Derecho de Seguros (Santiago, Chile, Legal Publishing) 760 p.

Corral, Hernán (2013), Lecciones de responsabilidad civil extracontractual, Santiago, Chile: Legal Publishing, 475 pp.

Del Arco, Miguel y Pons, Manuel (2010): Derecho de la construcción. Aspectos administrativos y civiles (Granada, España, Comares, octava edición) 605 pp.

De Solminihac, Hernán, y Thenoux, Guillermo (2017): Procesos y técnicas de construcción (Santiago, Chile, Ediciones UC, sexta edición) 543 pp.

Delvincourt, M. (1827): Cours de Code Civil, Tome Septieme, Nouvelle Edition (Bruxelles: P.J. de Mat) 502 pp. Disponible en:: https://ia800203.us.archive.org/15/items/coursdecodecivil07delv/coursdecodecivil07delv_bw.pdf (Fecha de consulta: 2 de febrero de 2018).

ERbetTA, Andrés (2017): "La cesación unilateral del contrato de obra prevista en el artículo 1999, inciso $2^{\circ}$, del Código Civil”, Revista Chilena de Derecho Privado, No 28, pp. 9-51. 
FÉdération Internationale des InGÉnIerus-Conseils (FIDIC) (2011), FIDIC Procurement Procedures Guide, $1^{\text {st }}$ edition, Ginebra, Suiza: Fédération Internationale des IngénierusConseils, 256 pp.

FÉdÉRATION INTERNATIONALE DES INGÉNIERUs-CONSEILS (FIDIC), FIDIC Conditions of Contracts for Construction (1999), $1^{\text {st }}$ edition, Ginebra, Suiza: Fédération Internationale des IngénierusConseils. Citado como FIDIC RED BOOK (1999).

Figueroa VAldÉs, Juan Eduardo (2013): "Los contratos de construcción FIDIC frente al derecho chileno", Gaceta Jurídica No 394, pp. 7-24.

Ferrante, Alfredo (2012): Open Price y compraventa (Cizur Menor, Thomson Reuters), 294 p.

Fleischmann, Hernán y León, Juan Ignacio, 2017: "El programa de trabajo como fuente de obligaciones en el contrato de construcción”, en Figueroa, Juan Eduardo (Coord.), Derecho de Construcción. Análisis dogmático y práctico, Santiago, Der Ediciones, pp. 93-116.

García Goyena, Florencio (1852): Concordancias, motivos y comentarios del Código Civil español, cuatro volúmenes Madrid, Imprenta de la Sociedad Tipográfico-Editorial (citado por la edición facsímil de 1973, Barcelona, Editorial Base).

Hughes, Will; Champion, Ronan; Murdoch, John (2015): Construction Contracts. Law and Management (London, U.K., Routledge, fifth edition), $435 \mathrm{p}$.

Huidobro, J., Heredia, B.; Salmona, M.; Alvarado, L. (2004): "Inclusión de la gestión de riesgos en el estudio de ofertas para licitaciones de proyectos de construcción”, Revista de la construcción, Vol. $8 \mathrm{~N}^{\circ}$ 2:, pp. 37-37.

KLEe, Lukas, 2015: International Construction Contract Law, Oxford: Wiley \& Sons, Ltd.

Meza Barros, Ramón (2010): Manual de Derecho Civil. De las fuentes de las obligaciones, Tomo I (Santiago, Chile, Editorial Jurídica de Chile (se cita por referencia a párrafos numerados).

Molina, Carlos y Ríos, Víctor (2016): Derecho de la construcción (Santiago, Chile, O’Print Impresores), $472 \mathrm{p}$.

Pothier, R. J. (1778): Traité du contrat de louage, Nouvelle Edition (Paris, Chez les Freres Debure, Nouvelle Edition) 464 pp. Disponible en: https://gallica.bnf.fr/ark:/12148/ bpt6k9610544f? rk=42918;4 (Fecha de consulta: 18 de diciembre de 2018).

Podetti, Humberto, 2004: Contrato de construcción, Buenos Aires: Astrea.

Prado Puga, Arturo (2014), "El contrato general de construcción y en especial la modalidad EPC y sus principales características”, Revista Chilena de Derecho, vol. 41, No 2: pp. 765-783.

Ríos, Víctor, 2017: "La fuerza mayor en los contratos de construcción”, en Figueroa, Juan Eduardo (Coord.), Derecho de Construcción. Análisis dogmático y práctico, Santiago, Der Ediciones, pp. 215-203.

RodríGuez, María Sara (2017): “Cargas de colaboración y distribución de riesgos en el contrato de construcción”, en Corral, Hernán y Manterola, Pablo (Coord..), Estudios de Derecho Civil XII (Santiago, Chile, Thomson Reuters), pp. 321-340.

Rodríguez, María Sara (2018): "Lecciones de un análisis comparado de distribución de riesgos del contrato de construcción con algunos modelos estandarizados internacionales", en Bahamondes, Claudia et. al (Coord..), Estudios de Derecho Civil XIII (Santiago, Chile, Thomson Reuters), pp. 455-482.

Serpell, Alfredo; y Alarcón, Luis (2017): Planificación y control de proyectos (Santiago, Chile, Ediciones UC, cuarta edición), 264 p.

SAN MARTín, Lilian (2016): "Contrato para la confección de obra material. Naturaleza jurídica y otros problemas dogmáticos”, Revista de Derecho Universidad Católica del Norte, Año 23 $\mathrm{N}^{\circ}$ 2, pp. 145-179.

Southerland, Thomas (2014): "Condiciones imprevistas en los contratos de construcción a suma alzada y su aplicación al sitio de las obras”, Revista Chilena de Derecho Privado, $\mathrm{N}^{\circ} 22$, pp. 161-195. 
UfF, John (2013): Construction Law (London, U.K., Sweet \& Maxwell, eleventh edition) 548 p.

Vial, Felipe y Mackenna, Juan (2005): Dificultades que se presentan comúnmente en la etapa de licitación y durante la construcción (Santiago, Chile, Instituto del Cemento y del Hormigón de Chile) 24 pp. (documento no publicado en poder de la autora).

Wagemann, Alex y Mereminskaya, Elina (2017): "La formación del consentimiento en el contrato de construcción de obra privada. El rol de las aclaraciones y respuestas a consultas", en Figueroa, Juan Eduardo (Coord.), Derecho de Construcción. Análisis dogmático y práctico (Santiago, Chile, Der Ediciones), pp. 7-24.

\section{Normas citadas}

\section{Código Civil de Chile.}

Código de Procedimiento Civil de Chile.

DeCreto Supremo 75, Reglamento PARA CONTRATOS De obras Públicas (RCOP), publicado el 1 de diciembre de 2004.

Decreto Supremo 1093, Reglamento de montos de Contratos De obras Públicas, publicado el 29 de noviembre de 2003.

Decreto Supremo 236, Bases generales reglamentarias para contratos de ejecución de obras [de edificación y urbanización] de los Servicios de Vivienda y Urbanización [del Estado], publicado el 1 de julio de 2003.

Decreto Supremo 48 , Reglamento para la contratación de trabajos de consultoría del Ministerio de Obras Públicas, publicado el 28 de febrero de 1994.

Decreto con Fuerza de Ley 458, Ley General de Urbanismo y Construcciones (LGUC), publicado el 13 de abril de 1976.

Decreto Ley 825, Ley sobre impuesto a las ventas y servicios (IVA), publicado el 31 de diciembre de 1974.

Decreto Supremo 55, Reglamento de la ley del IVA, publicado el 2 de febrero de 1977.

Código Civil Francés. Disponible en: https://www.legifrance.gouv.fr/telecharger_pdf.do?cid Texte=LEGITEXT000006070721 (Fecha de consulta: 18 de enero de 2018) (traducción no oficial).

\section{Jurisprudencia citada}

Corte Suprema de Chile (Tercera Sala), sentencia de 30 de agosto de 2016, rol 33634-2015.

Corte Suprema de Chile, sentencia de 8 de octubre de 2015, rol 32.960-14.

Corte Suprema de Chile (Tercera Sala), sentencia de 21 de abril de 2014, rol 2274-2013.

Conte Suprema (Tercera Sala), sentencia de 26 de septiembre de 2013, rol 375-2013.

Corte Suprema de Chile (Tercera Sala), sentencia de 7 de junio de 2017, rol 52960-2016.

Centro de Arbitraje y Mediación (CÁmara de Comercio de Santiago), sentencia de 29 de junio de 2010, rol 1087-2009 (Andrés Cuneo Macchiavello). Disponible en: http://www.camsantiago.cl/sentencias/IndiceGral_2011/1087.pdf (Fecha de consulta: 29 de diciembre de 2017).

Centro de Arbitraje y Mediación (CAMara de Comercio de Santiago), sentencia de 8 de marzo de 2006, rol 461-2006 (Blas Belollio). Disponible en: http://www.camsantiago.cl/sentencias/ IndiceGral_2011/461.pdf (Fecha de consulta: 29 de diciembre de 2017).

Centro de Arbitraje y Mediación (CAmara de Comercio de Santiago), sentencia de 18 de julio de 2005, rol 444-2005 (Claudio Illanes). Disponible en: http://www.camsantiago.cl/ sentencias/IndiceGral_2011/444.pdf (Fecha de consulta: 29 de diciembre de 2017). 
Centro de Arbitraje y Mediación (Cámara de Comercio de Santiago), sentencia de 22 de noviembre de 2004, rol 364-2004 (Luis Óscar Herrera). Disponible en: http://www.camsantiago.cl/sentencias/IndiceGral_2011/364.pdf (Fecha de consulta: 29 de diciembre de 2017). 
